\title{
Information sources, knowledge and compliance to COVID-19 safety protocol in Borno State, Nigeria
}

\author{
Joseph Wilson ${ }^{1}$ \\ University of Maiduguri, Nigeria \\ Chima Onuekwe \\ WHO Emergency Preparedness and Response \\ North-East Nigeria, Maiduguri, Borno State \\ Abdulmutallib Ado Abubakar \\ University of Maiduguri, Nigeria \\ Collins Owili \\ Henry Okoro-Nwanja \\ WHO Emergency Preparedness and Response \\ North-East Nigeria, Maiduguri, Borno State
}

To cite this article: Wilson, J., Onuekwe, C., Abubakar, A.A., Owili, C., \& OkoroNwanja, H. (2021). Information sources, knowledge and compliance to COVID-19 safety protocol in Borno State, Nigeria. World of Media. Journal of Russian Media and Journalism Studies 4: 55-82. DOI: 10.30547/worldofmedia.4.2021.3

\begin{abstract}
Borno State, Nigeria has experienced active COVID-19 with quite a number of cases and mortalities. The extensive global campaign to create awareness about the pandemic and safety measures through various stakeholders appeared to have worked, especially when it became obvious that people in Borno keyed into safety protocols and observed the lockdown. They wore face masks, routinely applied hand sanitizers and handwashing in public places. It was observed, at some points however, there was obvious nonadherence to these protocols. Therefore, this study examines adherence to COVID-19 safety protocol issues in the state. Could the noncompliance be by those not aware or knowledgeable about the pandemic? Are there issues with the sources of information? The objectives of the study are to determine: the sources of information/knowledge on COVID-19; the effectiveness of the sources of information/knowledge on COVID-19; level of compliance to

\footnotetext{
${ }^{1}$ Corresponding author:

Joseph Wilson, Department of Mass Communication, University of Maiduguri, 1069 Bama - Maiduguri Rd, 600104, Maiduguri, Nigeria.

Email: wilson@unimaid.edu.ng
} 
COVID-19 preventive/safety measures, and to identify challenges in complying with COVID-19 safety/preventive measures. The study used knowledge, attitude and practice theory employed survey method as well as convenience and purposive sampling techniques to select 2949 respondents across three LGAs in the state. The study found that people are aware and knowledgeable about the pandemic. The mass media, especially radio are the major sources of information. The noncompliance to COVID-19 safety protocol is largely due lack of fund to purchase and use face mask and hand sanitizer. It concludes that there are diverse sources of knowledge and information with poor compliance to the safety protocols in Borno State.

\section{Keywords}

COVID-19, Borno, safety protocol, compliance

\section{Introduction}

Since the outbreak of COVID-19, nations have taken steps to create awareness and ensure that people are knowledgeable about how to protect themselves and prevent further spread of the disease. The World Health Organization working with other relevant stakeholders at national and local levels ensured there was consistency in the level of awareness and risk communication messages available to the population. Messages were shared through different media platforms and other sources of information around the world to create awareness and reduce the spread of the virus. It was found in countries such as Ethiopia and the USA that people who had access to multiple informal and formal sources of information such as radio, television and Internet as well as health workers and peer groups have better understanding of the virus, trust the information and more willing to comply with the safety protocols (Awake et al., 2020; Maykrantz et al., 2020). Similarly, Ali and Bhatti (2020) discovered in Asia that media and other sources of information played fundamental roles in informing and triggering willingness among general public and health workers to believe and comply with safety issues of COVID-19. Consequently, the positive connection between media, information sources and motivation to comply with measure of addressing the pandemic had been established in many countries and communities around the world such Portugal, Germany, and Sweden (Arriaga et al., 2021). These scholars established that media could be used for effective health communication during COVID pandemic; the diffusion of fake information about COVID-19 through the media especially social media platforms and willingness of some people to accept, believe or act based on fake information; information as one factor that contributes to compliance on the 
safety measures; and the role of media in making people connected during the pandemic period.

It is based on the WHO's efforts and what was obtainable in other parts of the globe that Borno State in north-eastern Nigerian also keyed into the campaign, trained, and engaged stakeholders such as the media practitioners, health workers, religious and community leaders to boost awareness and knowledge about the pandemic in Borno State, even before the state recorded its index case. While this was ongoing, Borno State confirmed its COVID-19 index case on 18 April, 2020 and ever since, it has continued to record cases as testing continues. At some point Borno State topped the list of the number of cases in the North-east region ${ }^{2}$.

As indicated, the state has been proactive in putting measures to contain the pandemic even before it recorded its index case and this effort has continued to minimize the spread or increase in COVID-19 cases. For instance, it established the State Task Force on COVID-19 Response and activated the Public Health Emergency Operations Center (PHEOC). The WHO trained state and local government areas Rapid Response Teams (RRT), decontaminating health facilities where the index case in Borno State was admitted and hitherto providing technical support to ministry of health in Borno in active surveillance, risk communication, contact tracing, setting up isolation Centre for treatment of COVID-19 patients, sensitization/education on importance of preventive measures ${ }^{3} \&^{4}$.

Like other 36 states in Nigeria, the Borno State Task Force on COVID-19 Response enforced both intra and interstate restriction of movement (the lockdown) and encouraged residents to maintain social distancing, use of local hand sanitizers and face masks as part of nonpharmaceutical preventive behaviour ${ }^{5}$.

During the early lockdown days, it was observed that there was high-level compliance among residents of the state on safety and preventive measures, especially maintaining social distancing, use of local hand sanitizers and face

\footnotetext{
${ }^{2}$ Nairametrics (2020). COVID-19 update in Nigeria. Available from: https://nairametrics.com/2020/07/15/covid-19-update-in-nigeria/

${ }^{3}$ WHO (2020). WHO scales up support as Borno State confirms COVID-19 outbreak. Available from: https://www.afro.who.int/news/who-scales-support-bornostate-confirms-covid-19-outbreak.

${ }^{4}$ CRC (2020). ICRC response to COVID-19 in Nigeria. ICRC.

${ }^{5}$ No face mask, no entering markets in Borno. Today, 25th April, 2020. Available from: https://www.today.ng/news/nigeria/face-mask-entering-markets-borno-294382
} 
masks as part of preventive behaviour. For example, residents observed social distancing in the use of tricycles, in worship places, handshakes were minimised, face masks were visibly seen among vehicle passengers, gathering and shopping centres. Water and liquid soaps/hand sanitizers were distributed and visibly seen as well as used in public/commercial building with a good number of residents having same in their houses.

Despite some success on the compliance with the preventive measures among the high and middle classes in the state, the same cannot be said among the people who are considered as lower class who resided in more congested settlements on their level of compliance to preventive behaviours. Among the 'lower' and indeed high and middle classes, it was also observed that there was decline in adhering to social distancing, use of face masks, washing of hands with soap and use of hand sanitizer lately and people have been observed to have reverted to the usual handshake. Hence, there is no empirical evidence that show the information sources and compliance with COVID-19 protocols in Borno State, which might have contributed, like other parts of the world, to increase or sudden decline in the compliance to COVID-19 safety and preventive behaviours as noticed in Borno State, especially considering that there are daily reported cases both in the state and in the North-east region of the country. Furthermore, considering the centrality of information and knowledge on issues of no pharmaceutical preventive measures, this study examined the sources of information and knowledge on COVID-19 as well as the effectiveness of these sources among the target population. The research focused on residents of the Maiduguri Municipal Council, Gwoza town in Gwoza LGA and Monguno town in Monguno Local Government Areas. Although the population of these areas could not be ascertained because of the insurgency that had displaced people or residents, there were available figures based on 2006 Nigerian Census and projections based on the census figure. It had been reported that 2.7 million internally displaced persons (IDPs) in north-eastern. Therefore, this study contributes immensely to understanding the connection between information source and behaviour change on COVID-19 issues. It would help policy makers in the state to understand the reasons for the sudden decline in COVID-19 safety and preventive behaviour among residents and provide innovative ways to encourage or enforce compliance by the state and development partners. Further, this study would be a useful government to enhance its efforts to minimize the increase in the spread of the pandemic and it would further guide the stakeholders on COVID-19 campaign strategies.

The objectives of this research are to determine the sources of information/ knowledge on COVID-19; to determine the effectiveness of the sources of 
information/knowledge on COVID-19; to determine COVID-19 preventive/ safety measures compliance status; and identify information sources and challenges in complying with COVID-19 safety/preventive measures.

\section{Knowledge and sources of pandemic and compliance to prevention measures}

Knowledge and sources of information on pandemic and health issues determine how people perceive and believe about a pandemic and act in order to prevent themselves and others from it. Al-Hanawi et al. (2020) argued that knowledge of pandemic like COVID-19 centres on knowing and understanding 'the causes and transmission sources of a disease, increases the likelihood that people will become more aware of the spread of communicable diseases, and of the preventive measures to slow transmission' (Al-Hanawi et al., 2020). This requires many information sources such as mass media especially in developing societies like Borno State where there is a humanitarian crisis that has affected women and children for over a decade. This crisis might have affected access to information.

The Nigeria's Demographic and Health Survey NDHS (2019) stated that the percentage of women and men who accessed information through newspaper, radio and television on a weekly basis in Borno State as $76.8 \%$. The report disaggregates the figure as $2.2 \%, 18.4 \%, 13.3 \%$ and $1.4 \%$ for newspaper, radio, television and combination of three media respectively. This however has given clear picture of access to sources of information because the survey did not cover 11 local governments out of 27 because of Boko Haram insecurity (NDHS, 2019). The findings suggest that many women and girls had little access to information about HIV/AIDS and GBV and by extension COVID-19 pandemic.

The NDHS (2019) report further stated that sources of knowledge and information for men and women in Borno State were different. On family planning issue, the survey discovered that out of 1,469 women interviewed only $8.5 \%, 2.7 \%, 0.7 \%$, and $1.6 \%$ had radio, television, newspaper/magazine, and mobile phone respectively as sources of information. Social media, poster, leaflet/brochure, town crier and mobile public announcement as sources of information had $1.8 \%, 4.7 \%, 0.5 \%$ and $0.3 \%$ respectively. This shows that more than $80 \%$ of people sourced information from other sources than mass media. The figure for men was relatively higher with over $61.0 \%$ radio, $46.7 \%$ television and $30.7 \%$ newspaper/magazine. Thus, media together with other sources provided public health campaigns against poliomyelitis, immunization, 
malaria control, HIV/AIDS pandemic, and Ebola Virus Disease (Odorume, 2015). Media is a significant instrument that serves as source of knowledge, understanding, dissemination and influencing perception, opinions, favourable attitudes, and right behaviours of public on many issues that included public health emergencies like COVID-19 (CDC, 2014; Odorume, 2015; Pan American Health Organisation, PAHO, 2020; WHO, 2005).

The media help in reaching out communities with knowledge and evidencebased messages for behaviour change messages that is achieved through use of appropriate media as sources of information and partnership with social media and technology companies to spread information about COVID-19 and mitigate fake information and generate knowledge and compliance (Tangcharoensathien et al., 2020). Thus, poor knowledge of health and access to health information can affect compliance with COVID-19 safety and preventive measures. Hence media is fundamental to control and eradication of the disease (Padidar, Liao, Magagula, Mahlaba, Nhlabats, \& Lukas, 2020).

According to Kayrite, Hailu, Tola, Adula, and Lambyo (2020), there was poor compliance to the prevention and safety protocols in Ethiopia due to poor access to information. Other reasons for lack of compliance might be associated to challenges related to income, poor political governance, and knowledge. According to Al-Hanawi (2020), however, people in Saudi Arabia had good knowledge, positive attitudes, and good practices toward COVID-19 protocols, which might be linked to level of development that can affect compliance. Therefore, the same cannot be the same in developing societies like Borno State.

\section{Information sources and challenges in complying with safety/preventive measures}

Complying or otherwise with safety protocols on pandemic is associated with access to information, knowledge, exposure, social status income and belief system. But information sources, such as media, are more central to the compliance dynamics in the COVID-19 context. According to Maykrantz, Gong, Petrolino, Nobiling and Houghton (2020), people who have access to information on COVID-19 through formal sources, such as radio, television and social media, were more prompt in complying with preventive measure. The information provided though unofficial sources of information is hard to believe, and people act accordingly. Media as a watchdog of the society set the public agenda on health matters, inform, educate, persuade people on public health emergencies and serve as a forum for discourses related to public health (Oyama \& Okpara, 
2017). This demonstrates that media provide leadership to the community, empowered society about potential health risks, physical education, and health literacy, and persistently advocating for adequate measures that can improve public health such as COVID-19 issues. Olubunmi, Ofurum, and Tob (2016) stated that information sources, particularly media, were effective in reaching a larger audience but less effective in enforcing behavioural changes. Television has been found to be instrumental in reaching teenagers and adolescents and radio seems to be the most operational broadcast option in reaching out to rural communities besides other interpersonal communication channels (Olubunmi, Ofurum, \& Tob, 2016). Many sources of information, especially conventional media, try to stop the spread of fake information that may affect compliance with preventive protocols because they care about credibility and reputation and adherence to professionalism as universal convention. The bulk of fake information on the pandemic that may affect compliance is disseminated on social media and is based on it. Cinelli et al. (2020) argued that questionable information about COVID-19 was spread on social media platforms like Twitter, Instagram, WhatsApp and Facebook. This will likely affect adhering to messages received on social media.

On the other hand, studies have shown there are different positions on the impact of income and health. Some have argued that it is difficult to isolate the impact of income on health because of the linkage between income and other social risk factors. Moreover, it has been shown that people with higher incomes tend to live in healthier ${ }^{6}$. Similarly, people with low income are likely to be unable to have knowledge on how afford care and use fewer preventive care services ${ }^{7}$. Although a limited view, others argue that societies that high level of income inequality could have poor average health for reasons other than income distribution ${ }^{8}$. Although income is a factor, the COVID-19 pandemic have a number of alternative preventive measures that are cheap, affordable and effective by respective of income level or class. For example, social distancing, handwashing, stay-at-home and use of face mask (varieties) are affordable

${ }^{6}$ CHOKSHI, D. A. (2018). Health, income, \& poverty: Where we are \& what could help. Available from: https://www.healthaffairs.org/do/10.1377/ hpb20180817.901935/full/

${ }^{7}$ CUNNINGHAM, P. J. (2018). Why even healthy low-income people have greater health risks than higher-income people. Available from: https://www.commonwealthfund.org/blog/2018/healthy-low-income-people-greater-health-risks

${ }^{8}$ MARMOT, M. (2002). The influence of income on health: Views of an epidemiologist. Health Affairs, 21(2). Available from: https://www.healthaffairs.org/doi/ full/10.1377/hlthaff.21.2.31 
practices 9 .Padidar, Liao, Magagula, Mahlaba, Nhlabats and Lukas (2020) stated that people with higher level of education and income were more aware of the pandemic but there was challenge related to compliance to the safety measures.

\section{Theoretical framework}

This study is based on the arguments of knowledge, attitude and practice theory. This theory, which is also referred to knowledge, attitude and behaviour, is attributed to studies in health and other development interventions. The theory, which is associated to Schwartz (1976), states that level of knowledge on health issues like COVID-19 that are shared and sourced on media or other information platforms could impact on how people perceive the issue and possibly behave towards it or against it. The behaviour encompasses compliance or otherwise to an idea sourced from media or any information source. Thus, people can conform to safety and prevention protocols on COVID-19 because of the knowledge they accumulate through media or other sources of information. On the other hand, people could refuse to comply with guidelines despite the high level of knowledge due to preexisting cultural, traditional and religious (Al-Hanawi, 2020; Kayrite et al., 2020).

\section{Methods}

The research drew its study population (sample) from the target population using the multistage approach. The Stage one involved categorizing the state into the three senatorial districts of the state (Borno North, Borno Central and Borno South). The Stage two purposively selected one LGA from each of the senatorial districts, based on the LGA with the highest number of recorded COVID-19 cases. The selected LGA were: Maiduguri Metropolitan Council, Monguno and Gwoza. In Stage three, respondents were selected for administration of questionnaires and FGD meetings, based on residents of the LGAs from the period of confirmed cases of COVID-19 in Borno State to when the fieldwork started and ended (April to September 2020). The confirmed case in Borno marked the beginning of official observation of safety measures for residents. 3240 questionnaires were administered equally among the respondents in three LGA (proportional sampling fraction: MMC 1080, Gwoza 1080 and Monguno 1080) and Six FGD sessions made up Eight participants were

${ }^{9}$ YAMEY, G. (2020). We have a cheap, effective way to keep ourselves safer from COVID-19. Why are we fighting about it? TIME, 29th June, 2020. Available from: https://time.com/5861295/masks-covid19-spread-fighting/ 
conducted in each of the selected LGAs. Thus, a total of 3240 questionnaires were administered to respondents and retrieved, 2949 were found usable, which represent 91 percent return rate. 291 representing 9 percent were not found usable, largely because of the respondents' claim of lack of knowledge of the COVID-19 pandemic. The usable sample consists of 2949 respondents that cut across the three selected Local Government Areas (Maiduguri Municipal Council (MMC) 930, Gwoza 984 and Monguno, 1035. The FGD consisted of a total of 144 discussants participated in the FGD 18 session across the three LGAs. 6 FGD sessions each for MMC, Gwoza and Monguno were conducted. Each session was made up of 8 participants. The fieldwork took place between August 25, and September 8, 2020. The demographic characteristics relation to gender, age and educational background were considered in data collection. The gender of the respondents was 1858 (63\%) males and 1091 (37\%) females. For the FGD, participants for MMC, Gwoza and Monguno LGAs included 24 males and 24 females. The demographic age of respondents included 20 - below years 619 (21\%) respondents, 21 - 30 years, 1003 (34\%) respondents, 31 - 40 years, $708(24 \%)$ respondents, 41 - 50 years, 354 (12\%) respondents, $51-60$ years, $206(7 \%)$ respondents, and 61 - above years, 59 (2\%) respondents. Most of the FGD respondents across the three LGAs were predominantly within the ages of 31 to 40 and 21 to 30 age categories. The broader picture of educational attainment of the respondents considered in this study indicated that there were more respondents with Diploma and National Certificate of Education in respect of educational attainment. Most of the participants across the three LGAs have attained diploma or National certificate of education level, which is an indication of more educated participants across the three LGA. The result is a pointer that most survey respondents and FGD participants have attained the tertiary level of education, which should ordinarily translate to more knowledge on the COVID-19 pandemic, perhaps issues of compliance and healthier status ${ }^{10}$. As a rule, among the population studied there are more of those who have achieved one level of education than those who have not. This demographic information adequately represented the population of reported COVID cases, but it only relatively represented the general population in selected areas that are populated and inaccessible to researchers due to the Boko Haram insurgency and lack of internet connectivity.

${ }^{10}$ UoPeople (n.d). Benefits of education are societal and personal. Available from: https://www.uopeople.edu/blog/benefits-of-education-are-societal-and-personal/ 


\section{Findings}

\section{Knowledge of COVID-19}

The knowledge of respondents on the COVID-19 pandemic acquired through various information sources that could determine the compliance to safety measures in the three LGAs is presented below.

\section{Knowledge of COVID-19}

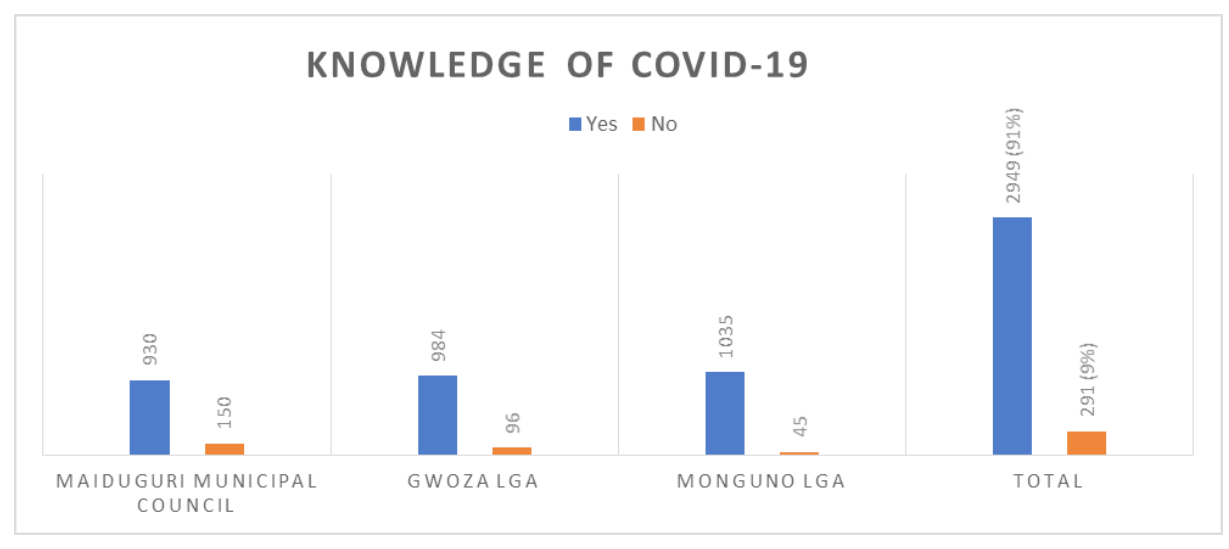

Source: Field work 2020

Respondents were asked to indicate whether they have knowledge of COVID-19. Figure 1 shows that most of the respondents in the three LGAs have knowledge of COVID-19. However, there were respondents that claimed they did not know of COVID-19. The result for Borno indicates that $91 \%$ of the respondents know of COVID-19, while 9\% do not know about COVID-19.

Most of the FGD participants across the three LGAs noted that they know of COVID-19 pandemic. However, the few who did not know joined the discussion when they finally understood the issues under discussion. It indicates that some respondents did not know what COVID-19 is but had ideas about the pandemic and were able to make contributions in the discussion. For example, some of the participants claimed: 'We don't have knowledge about it, but we heard what is on the radio, TV, hospital, NGOs, relatives, religious leaders, community leaders ${ }^{11}$. The participants across the three LGA went on to even identify the mode of transmission of the disease, such as transmission through droplets

${ }^{11}$ FGD participants explanation on knowledge of COVID-19. 
from sneezing, and coughing from a person having coronavirus; through direct contact with somebody who is carrying the virus; through contaminated objects and surface.

Obviously, you will hardly find residents of the selected local government and possibly Borno State that would claim a total ignorance of the pandemic, provided they are furnished with further explanation on COVID-19, as is the case with the FGD.

\section{When respondents first heard of COVID-19}

Figure 2

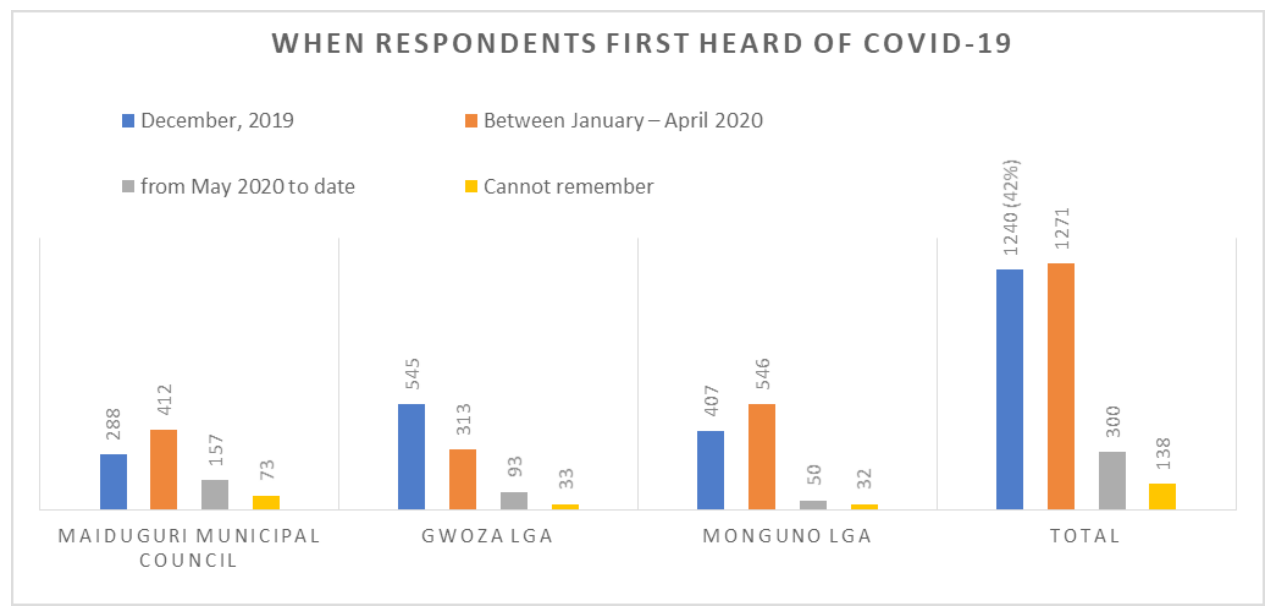

Source: Field work 2020

Result in respect of when the respondents first heard of COVID-19 is shown in Figure 2. In MMC and Monguno LGA, most of the respondents first found out about the pandemic between January to April 2020. In Gwoza most of the respondents knew about it in December 2019. It is further indicated that for Borno State most of the respondents, representing 43\% first heard of the pandemic between January to April, 2020. This is a further indication that most of the respondents have heard of the pandemic for over four or five months before this research and could have possible sought or been exposed to further knowledge on the pandemic.

\section{Sources of information and knowledge on COVID-19}

Sources of information and knowledge is a vital element in the information and knowledge management value chain. The effectiveness of these sources 
is equally important for proper information and knowledge delivery. Hence, respondents were asked to indicate their sources of knowledge on COVID-19 issues and the effectiveness of these sources in the selected LGAs.

Figure 3

\section{First source of information and knowledge on COVID-19}

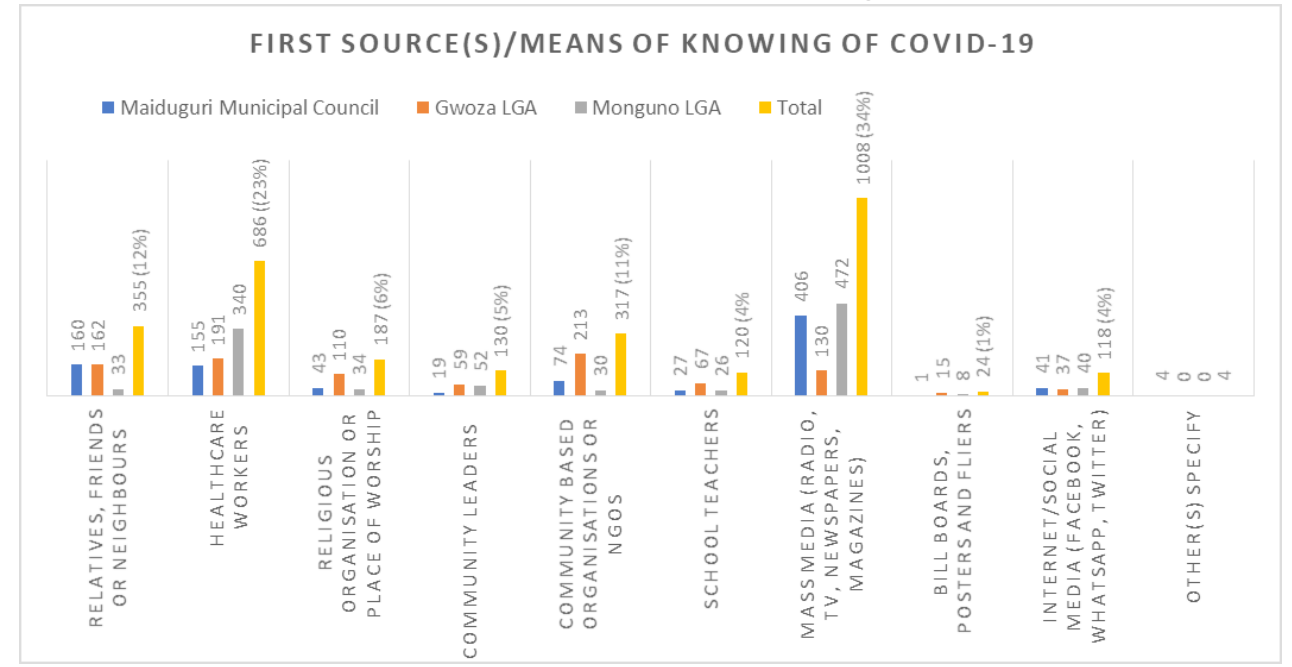

Source: Field work 2020

Figure 3 shows that most of the respondents in MMC and Monguno LGA indicated mass media as the first source of information about COVID-19. For Gwoza LGA, most of the respondents, their first information and knowledge of COVID-19 Community based organisations and NGOs. Generally, for Borno State the first source of information about the pandemic is mass media (34\%). It is followed closely by Health Worker $23 \%$. This is to show that while other sources are important, the centrality of mass media as the first source of information and knowledge to wider reach is important.

Although the FGD participants did not put emphasis on the first source of information and knowledge on COVID-19, they identified various sources, such as the social media, radio, friends and relatives, health workers, religious leaders, community leaders and NGOs. Interestingly, mass media as the popular and first source of information and knowledge on COVID-19 as identified in the survey result is reinforced by the FGD finding, especially as most of the participants across the LGAs identified the mass media as their source of information (radio and television), especially radio as a point of interest for the 
FGD participants in Gwoza LGA, who pointed out that the main advantage of radio is airing nonstop daily. Health workers are also important sources and means of delivering health information. Therefore, utilization of healthcare professionals for health information has been associated with meeting recommendations for health behaviours ${ }^{12}$, which is the focus of COVID-19 safety compliance. Since the discussion on information and knowledge on COVID-19 focused on the sources of information, the FGD finding in respect sources, as earlier pointed out, participants identified various sources, but emphasis on the mass media, especially, radio as a vital source of information and knowledge. This FGD position is a pointer to sources of information and knowledge on the pandemic.

\section{Effectiveness of sources of information and knowledge on COVID-19}

Table 1

\section{Rating of effectiveness of sources of information and knowledge} on COVID-19

\begin{tabular}{|l|c|c|c|c|c|}
\hline $\begin{array}{c}\text { Maiduguri Municipal } \\
\text { Council: Sources of } \\
\text { information about } \\
\text { COVID-19 }\end{array}$ & $\begin{array}{c}\text { Very } \\
\text { Effective }\end{array}$ & Effective & $\begin{array}{c}\text { Don't } \\
\text { Know }\end{array}$ & Ineffective & $\begin{array}{c}\text { Highly } \\
\text { Ineffective }\end{array}$ \\
\hline $\begin{array}{l}\text { Relatives, friends or } \\
\text { neighbors }\end{array}$ & 179 & 170 & 75 & 39 & 59 \\
\hline Healthcare workers & 244 & 154 & 48 & 127 & 151 \\
\hline $\begin{array}{l}\text { Religious organization } \\
\text { or place of worship }\end{array}$ & 140 & 157 & 90 & 42 & 67 \\
\hline Community leaders & 103 & 125 & 87 & 53 & 60 \\
\hline $\begin{array}{l}\text { Community based } \\
\text { organizations or NG0s }\end{array}$ & 123 & 170 & 70 & 57 & 50 \\
\hline School or teacher & 121 & 125 & 82 & 47 & 69 \\
\hline $\begin{array}{l}\text { Mass media } \\
\text { (radio, TV, } \\
\text { newspapers, } \\
\text { magazines }\end{array}$ & 264 & 202 & 58 & 36 & 58 \\
\hline
\end{tabular}

${ }^{12}$ REDMOND, N., BAER, H. J., CLARK, C. R., LIPSITZ, S., \& HICKS, L. S. (2010). Sources of health information related to preventive health behaviors in a national study. American Journal of Preventive Medicine, 38(6), pp. 620-627. DOI: https:// doi.org/10.1016/j.amepre.2010.03.001 
Abdulmutallib Ado Abubakar, Collins Owili, Henry Okoro-Nwanja

\begin{tabular}{|c|c|c|c|c|c|}
\hline $\begin{array}{l}\text { Internet/social media } \\
\text { (Facebook, WhatsApp, } \\
\text { Twitter, etc.) }\end{array}$ & 181 & 76 & 113 & 75 & 66 \\
\hline Others & 0 & 0 & 0 & 0 & 0 \\
\hline $\begin{array}{l}\text { Gwoza LGA: } \\
\text { Sources of information } \\
\text { about COVID-19 }\end{array}$ & $\begin{array}{c}\text { Very } \\
\text { Effective }\end{array}$ & Effective & $\begin{array}{l}\text { Don't } \\
\text { Know }\end{array}$ & Ineffective & $\begin{array}{c}\text { Highly } \\
\text { Ineffective }\end{array}$ \\
\hline $\begin{array}{l}\text { Relatives, friends or } \\
\text { neighbors }\end{array}$ & 219 & 159 & 34 & 48 & 57 \\
\hline Healthcare workers & 255 & 141 & 11 & 31 & 26 \\
\hline $\begin{array}{l}\text { Religious organization } \\
\text { or place of worship }\end{array}$ & 268 & 162 & 17 & 46 & 48 \\
\hline Community leaders & 113 & 201 & 15 & 19 & 30 \\
\hline $\begin{array}{l}\text { Community based } \\
\text { organizations or NGOs }\end{array}$ & 304 & 171 & 34 & 51 & 52 \\
\hline School or teacher & 235 & 205 & 43 & 61 & 89 \\
\hline $\begin{array}{l}\text { Mass media (radio, } \\
\text { TV, newspapers, } \\
\text { magazines }\end{array}$ & 252 & 244 & 59 & 31 & 34 \\
\hline $\begin{array}{l}\text { Internet/social media } \\
\text { (Facebook, WhatsApp, } \\
\text { Twitter, etc.) }\end{array}$ & 202 & 146 & 56 & 40 & 39 \\
\hline Others & 6 & 13 & 14 & 0 & 1 \\
\hline $\begin{array}{l}\text { Monguno LGA: } \\
\text { Sources of information } \\
\text { about COVID-19 }\end{array}$ & $\begin{array}{c}\text { Very } \\
\text { Effective }\end{array}$ & Effective & $\begin{array}{l}\text { Don't } \\
\text { Know }\end{array}$ & Ineffective & $\begin{array}{c}\text { Highly } \\
\text { Ineffective }\end{array}$ \\
\hline $\begin{array}{l}\text { Relatives, friends or } \\
\text { neighbors }\end{array}$ & 37 & 27 & 42 & 520 & 71 \\
\hline Healthcare workers & 352 & 196 & 22 & 26 & 27 \\
\hline $\begin{array}{l}\text { Religious organization } \\
\text { or place of worship }\end{array}$ & 283 & 71 & 304 & 45 & 25 \\
\hline Community leaders & 99 & 261 & 39 & 188 & 19 \\
\hline $\begin{array}{l}\text { Community based } \\
\text { organizations or NGOs }\end{array}$ & 279 & 79 & 28 & 58 & 21 \\
\hline School or teacher & 69 & 130 & 143 & 228 & 14 \\
\hline $\begin{array}{l}\text { Mass media (radio, } \\
\text { TV, newspapers, } \\
\text { magazines }\end{array}$ & 341 & 43 & 100 & 211 & 115 \\
\hline $\begin{array}{l}\text { Internet/social media } \\
\text { (Facebook, WhatsApp, } \\
\text { Twitter, etc.) }\end{array}$ & 179 & 56 & 224 & 212 & 19 \\
\hline Others & 8 & 27 & 6 & 8 & 9 \\
\hline
\end{tabular}

Source: Field work 2020 
Respondents in the selected LGAs rated the effectiveness of the sources of information and knowledge on COVID-19. Table 1 shows that mass media are very effective among the sources of information and knowledge on COVID-19 for most of the MMC respondents. Most of the respondents indicated the community-based organizations or NGOs as very effective and health care workers the very effective source for Monguno LGA respondents.

Furthermore, the summary of the rating of various sources effectiveness indicates mass media as a very effective source ( 858 entries) followed closely by health workers ( 851 entries) by the study population. It means that both sources could be effective for disseminating general health information and specifically the pandemic in Borno State.

The FGD's conclusion on the effectiveness of sources of information and knowledge about the pandemic does not differ from a broader perspective from the results of the survey, which determined that the media is very effective and closely monitored by health professionals. While several participants identified other sources such as health professionals, the internet, religious leaders, community leaders, and NGOs, the media is most effective for the majority of the participants. Some of the reasons advanced for their source choices are:

'The reason for choosing the health workers is [that] health workers have credible information on the virus compared to any other sources.'

'The internet is the most effective. My phone is always with me to browse and check for updates on the disease. Sometimes, I receive messages from NCDC on WhatsApp.'

'Religious leaders are the most effective because they are trusted by us, the people.'

'The mass media are the most effective because they have always been our source of information on almost everything, the information from the mass media is processed by very credible people. We always have our radio handy.'

Most of them identified the media as the most effective source of information with a focus on radio because of its availability and accessibility at all times. The FGD result underpins the survey finding in respect of the rating of the effectiveness of sources of information and Knowledge on COVID.

The finding in respect of the effectiveness rating of the sources of information and knowledge on COVID-19 braces the position that the media improve communication about health by reaching a wide audience, and radio and television are effective channels for convincing target audiences of behavior change, as well as for conveying important information and knowledge. ${ }^{13}$

${ }^{13}$ NAVEENA, N. (2015). Importance of mass media in communicating health messages: An analysis. IOSR Journal of Humanities and Social Science, 20(2), pp. 36-41. 


\section{COVID-19 preventive and safety measures compliance status}

Observance of the preventive/safety measures is central to addressing the spread of the virus. Respondents were asked to indicate their observance attitude towards COVID-19 preventive and safety advice (Use of face mask, maintaining social distance and frequent handwashing among others). The quantitative data in this study have shown that all the safety measures (regular handwashing with soap or alcohol-based sanitizer; use of face mask; maintaining social and physical distance; avoiding crowded places; avoiding touching eyes, nose and mouth with bare hands; covering of mouth and nose with bent elbow or a tissue when coughing or sneezing and staying at home) were observed by the respondents but the regular handwashing is the most observed protective measure in MMC. In Gwoza and Monguno, respondents indicated the face mask as the most observed COVID-19 protective measure.

The FGD participants across the three LGAs pointed out that they know about the COVID-19 safety. They observed and identified some of the measures to prevent COVID-19 and they went further to give some reasons for the compliance.

\section{Observance of COVID-19 protective measures since the onset of the outbreak}

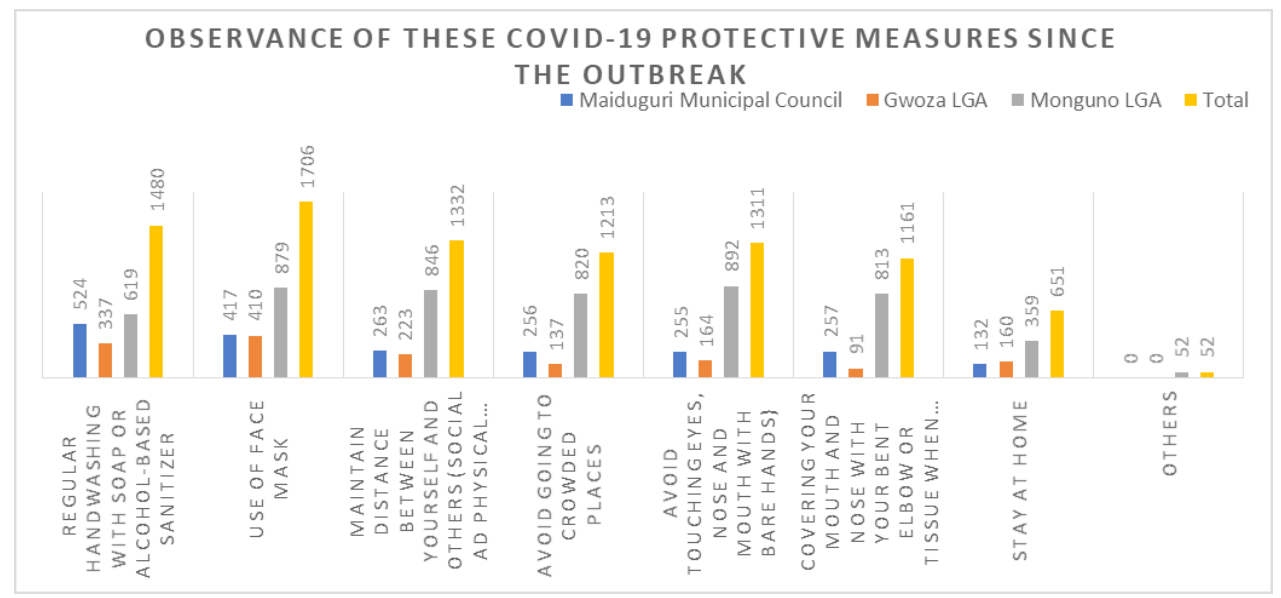

Source: Field work 2020 


\section{MMC participants:}

'Because it was a directive from the government.'

'I complied to protect myself and love ones from the disease.'

'I was scared of contracting the virus.'

'I complied because of the way the media reported the pandemic.'

\section{Gwoza LGA participants:}

'Because Government directives.'

'To avoid contracting the disease.'

'I feared contracting the disease, based on what we have been hearing on the radio.'

\section{Monguno LGA participants:}

'Because we are afraid of the deadly disease.'

'Government has taken serious action about the disease.'

This finding points the common observed and reported issues at the outbreak of the pandemic. The measures put in place received a wide compliance. Individuals and organizations ensured compliance to the safety measure. ${ }^{14}$

Figure 5

\section{Attitude to the use of face masks to prevent COVID-19 since the outbreak}

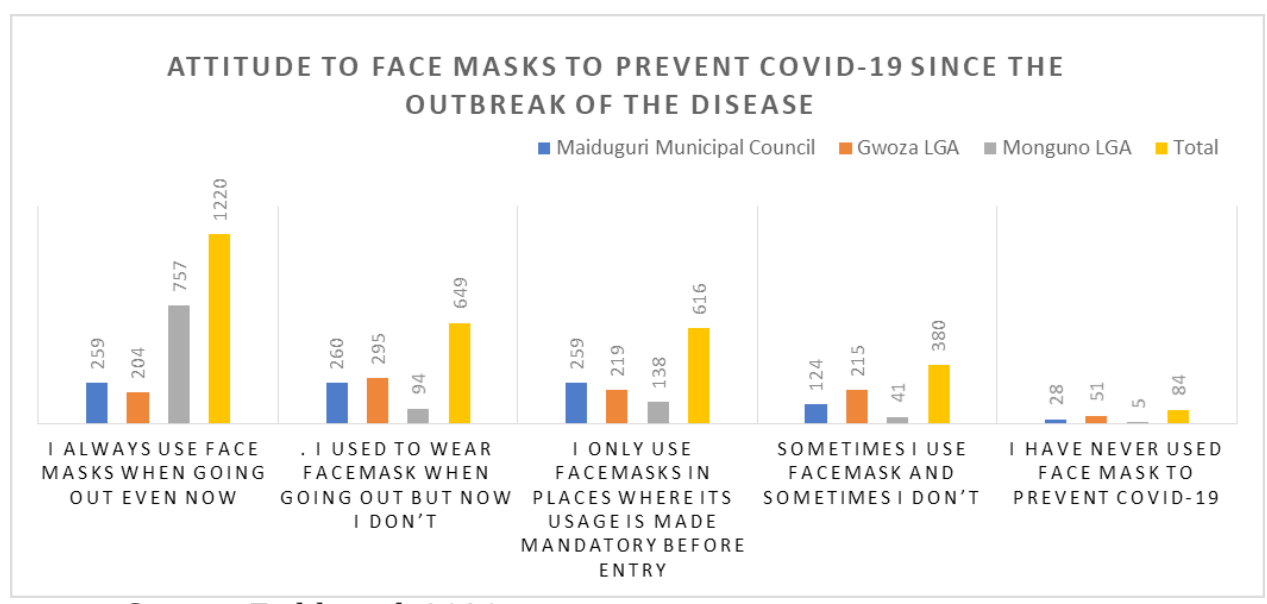

Source: Field work 2020

${ }^{14}$ OLAPEGBA, P.O., AYANDELE, O., KOLAWOLE, S.O., OGUNTAYO, R., GANDI, J.C., DANGIWA, A.L., OTTU, F.A., IORFA, S.K. (2020). A preliminary assessment of novel coronavirus (COVID-19) knowledge and perceptions in Nigeria. DOI: https://doi. org/10.1101/2020.04.11.20061408 
Respondents were asked to indicate their disposition to the use of face mask as a preventive measure to COVID-19 since the outbreak in the state. Most of the respondents in MMC and Gwoza LGA indicated that they used to wear face mask when going out but now they don't. In Monguno LGA, most of the respondents indicated that they always use face masks when going out even now. The general perspective in respect of Borno State (MMC, Gwoza and Monguno LGAs) as indicated in Figure 5, is that most of the respondents used face masks. There is still an adherence to use of a face mask as a preventive measure. The broader perspective is not unrelated to the use of face masks in places where it is made compulsory and could be linked to the high compliance level, especially in Monguno LGA, which resulted in 62\% response rate in respect of those who always use face masks when going out. However, the general perspective of the survey result, which showed that face masks are the most used, is closely followed by respondents who noted that they have stopped using face masks when going out.

The FGD result is not different from that of the survey respondents as most of the FGD participants across the selected LGAs noted that they observed the use of face masks along with other COVID-19 safety measures.

However, Figure 6 indicates that there is a decrease in the use of face mask across the selected LGAs. The decrease in the use of face masks more in MMC and Gwoza while there is a slight increase in Monguno. Nevertheless, most of the respondents $(63 \%)$ indicated that there is a decrease in face mask use.

Figure 6

Frequency of face mask usage now to prevent against COVID-19

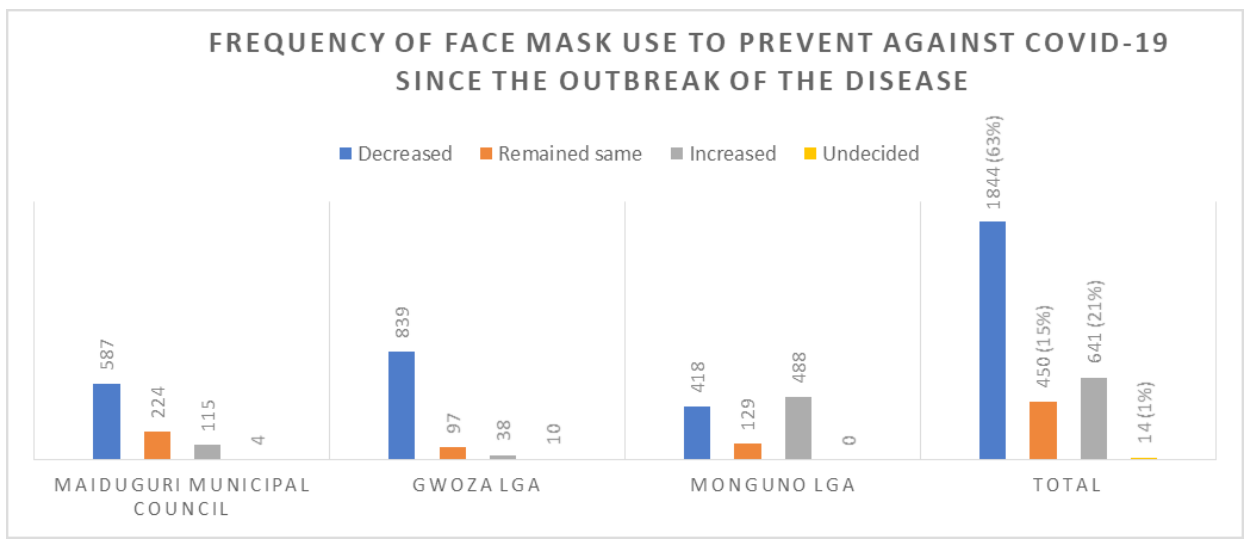

Source: Field work 2020 
The FGD participants across the selected LGAs noted that they have stopped observing some of the safety measures for COVID-19 prevention, While MMC and Gwoza indicated the use of a face mask as one of the safety protocols they have stopped observing. Participants in Monguno identified the following: 'Staying at home, observing social distancing except in most cases such as banks and hospitals.' The finding in respect of the decrease in face masks reinforces the position that Nigerians are abandoning the use of face masks and other safety protocols on COVID-19. ${ }^{15}$

Figure 7

\section{Reasons attributed for face mask usage status now to prevent against COVID-19}

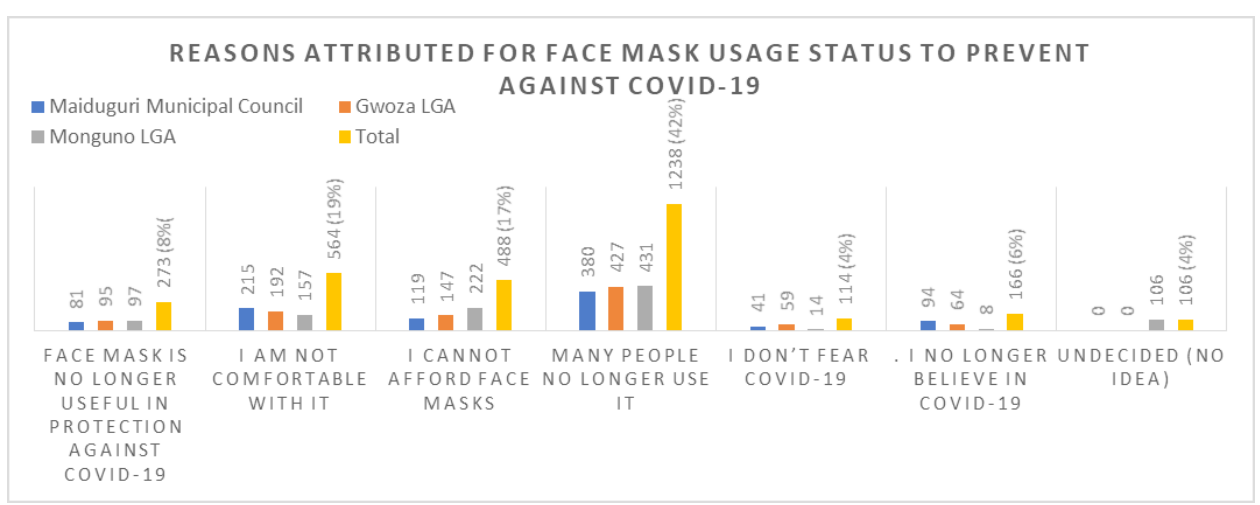

Source: Field work 2020

Respondents were asked to identify reasons for the decrease in the use of face mask as one of the COVID-19 preventive measures. Most of the respondents (42\%) across the selected LGAs indicated that the reason of the decrease is the bandwagon effect, that is those who use face masks have joined many other people who no longer use face masks. The FGD participants, especially in MMC and Gwoza noted that they have stopped the use of face masks and other COVID-19 and safety protocols because they have not seen any infected person, government no longer enforced the measures and the virus was scam. However, participants in Monguno did not indicate the stoppage of the use of face masks

${ }^{15}$ OJERINDE, D. (2020). COVID-19: Experts warn of second wave as Nigerians shun face masks. Healthwise, $7^{\text {th }}$ September, 2020. Available from: https://healthwise.punchng.com/covid-19-experts-warn-of-second-wave-as-nigerians-shun-facemasks / 
because 'people no longer observe the measures, the disease doesn't seem to be true and government lifted the lockdown rule.'

Figure 8

\section{Attitude to social distancing to prevent COVID-19 since the outbreak}

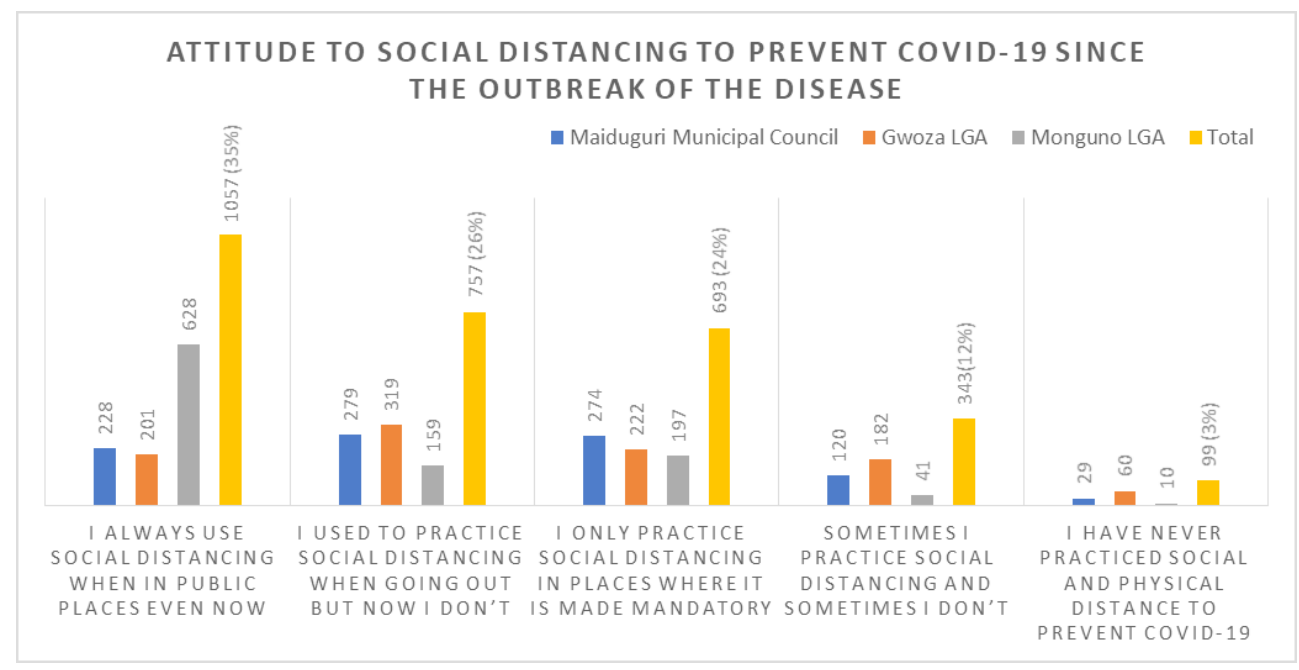

Source: Field work 2020

Attitude of respondents in respect of observing social distancing in public places varied. Monguno respondents indicated that they observe social distancing when in public. For Gwoza most of the respondents indicated that they used to practice social distancing, but no longer observe it. For MMC, most of the respondents only observe social distancing in places where it is made mandatory. Across the selected LGAs, most of the respondents (35\%) observed social distancing since the outbreak followed by respondents (26\%) that only observe or practice it where it is mandatory. On the other hand, most of the FGD participants noted that they practiced all the COVID-19 safety protocol, including maintaining social distance in public places before they stopped. This finding is an indication that all had been fine in respect of the compliance with the safety protocol before the decrease. 


\section{Reasons attributed for social distancing status against COVID-19}

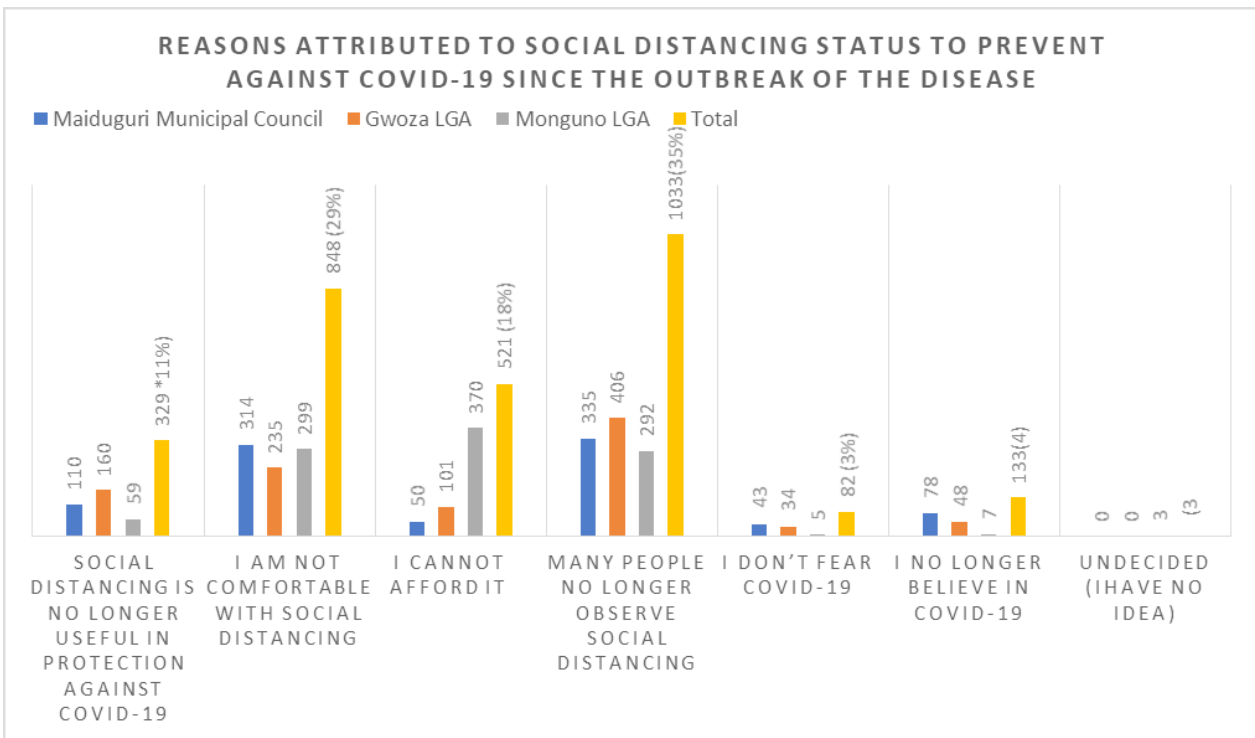

Source: Field work 2020

The reasons for the decrease in observing social distancing COVID-19 safety protocol is predominantly the same reason advanced for the decrease in the use of face masks, which is many people stopped observing social distancing because they joined the others who stopped or do not observe social distancing. It is shown that $35 \%$ of respondents have indicated the decrease because many people no longer observe social distancing. Other respondents indicated that they are not comfortable with social distancing (29\%). This finding goes to explain that observing social distancing is challenging. It has been pointed out that people around the world have not taken the observance of social distancing COVID-19 safety protocol seriously, which seems to be in Nigeria. There was a time, at the onset of the pandemic, social distancing was not one of the measures being required by government advisories in a place like Italy ${ }^{16}$.

${ }^{16}$ Nigeria Health Watch (2020). Coronavirus: Time to take social distancing seriously in Nigeria. Available from: https://medium.com/@nigeriahealthwatch/coronavirus-time-to-take-social-distancing-seriously-in-nigeria-8a059c881870 


\section{Attitude to handwashing to prevent COVID-19}

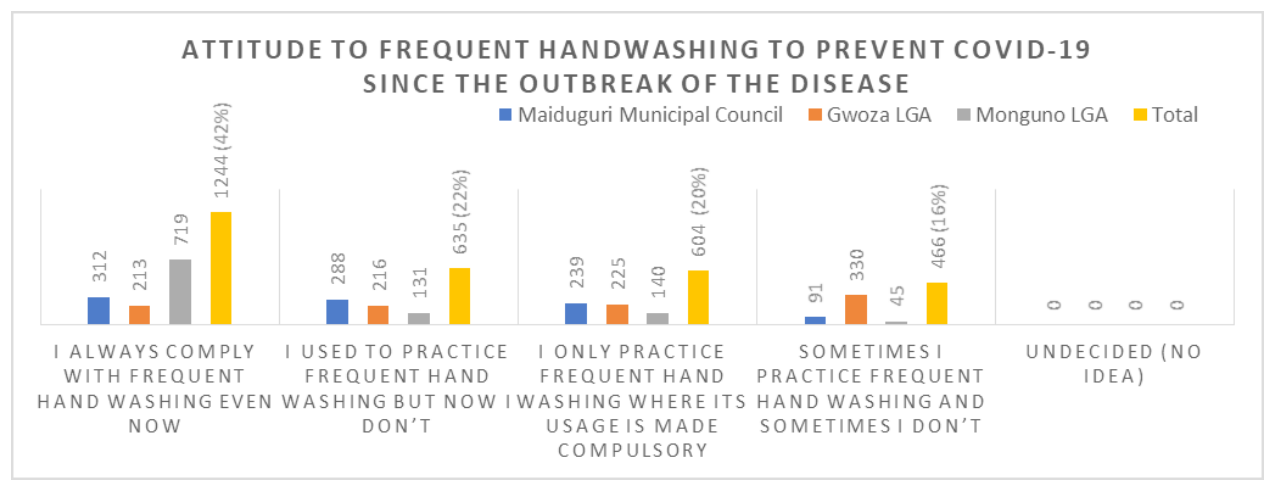

Source: Field work 2020

Most of the respondents (42\%) across the LGA practice handwashing as COVID-19 safety protocol. In spite the compliance, $22 \%$ of respondents no longer observe the handwashing practice and $20 \%$ practice it where and when it is compulsory.

Reasons attributed to handwashing status to prevent against COVID-19

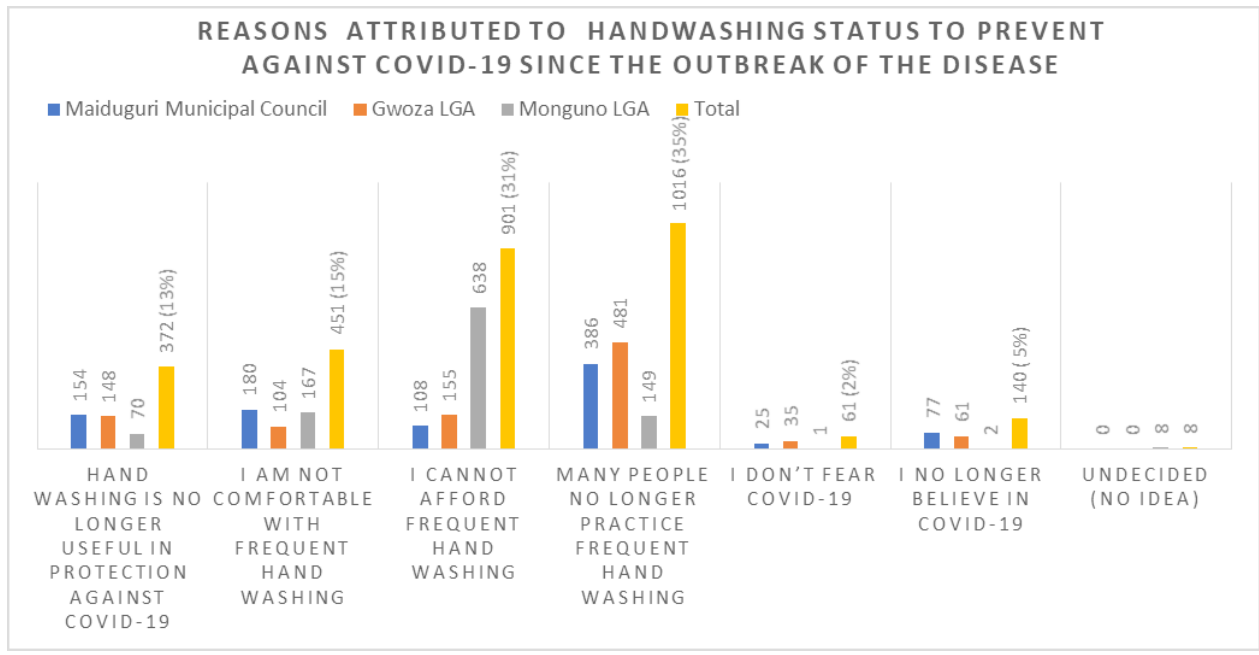

Source: Field work 2020 
Respondents were asked to indicate the reason for the decrease in observing regular handwashing as one of the COVID-19 safety protocols. It is shown that most respondents (35\%) across LGA indicated that many people no longer practice regular handwashing as they joined the others who no longer practice frequent handwashing. $32 \%$ of the respondents indicate that they cannot afford the regular handwashing. It seems simple, though there are arguments that many Nigerians would not be able to practice simple, cost-effective, life-saving protocol of frequent handwashing because of lack of access to clean water. WaterAid Nigeria has revealed that 55 million Nigerians lack access to safe pump water. $^{17}$

Challenges in complying with COVID-19 safety and preventive measures

Complying with the COVID-19 safety protocol is desirable. However, it comes with its challenges. Hence the research sought to identify challenges associated with compliance with the safety protocols in Borno State.

Figure 12

\section{Challenges in complying with COVID-19 safety measures}

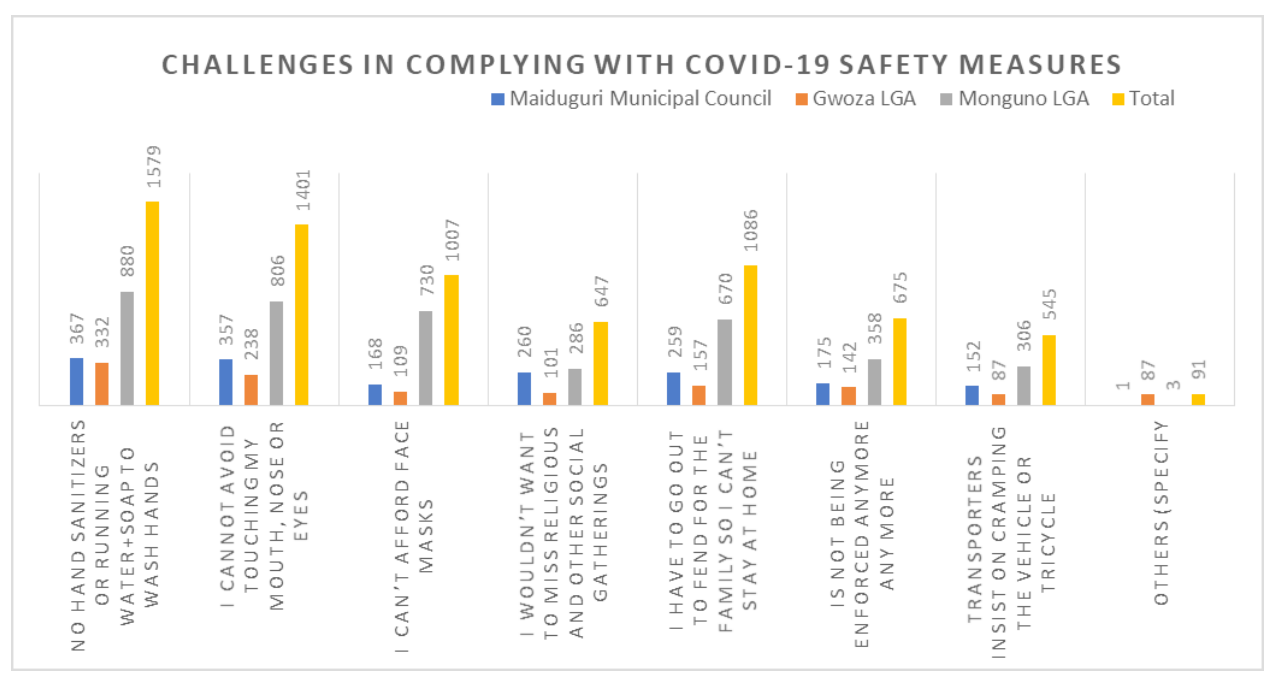

Source: Field work 2020

${ }^{17}$ ONWUZOO, A. (2020), COVID-19: Why regular handwashing is a challenge in Nigeria. Healthwise, 29th April, 2020. Available from: https://healthwise.punchng. com/covid-19-why-regular-hand-washing-is-a-challenge-in-nigeria/ 
Most of the respondents identified the lack of running water and hand sanitizer to comply to frequent handwashing. It followed by the inability to avoid touching mouth, nose and eyes. The FGD participants identified similar challenges as that of the survey respondents. Some of the challenges are:

'No running water to wash hands, I don't have money to buy hand sanitizer.'

'Motorists don't care about these measures - keke (tricycle) and buses will always want to overload.'

'If I stay at home, will the government come and feed my family? I have to go and look for what my family will eat.'

'Lack of provision of preventive and safety measure equipment by the Government.'

'Staying at home has become a hunger strike.'

'Most of the people cannot afford the equipment such as hand sanitizers and face mask.'

The FGD participants recommended government should reintroduce enforcement of compliance with the safety measures; it should make available face masks at affordable prices; it should enhance public sensitization and campaigns on compliance; and community and religious leaders should enhance their commitment to encouraging people to comply.

\section{Conclusion}

The research concludes that there are information sources which have not been utilized to stem the challenges in respect of compliance with the safety protocols of COVID-19. The study concluded that mass media is a very effective source (858 entries) followed closely by health workers (851 entries) in the study location. These challenges have manifested in the decrease in compliance across local communities in the state. Although residents are informed and have knowledge on COVID-19 and are aware of the safety protocols but there is decline in the use of face masks, observance of social distancing and regular handwashing, largely because many people no longer observe the protocols, as such, those who observe the protocol continue to abandon the safety measures. It is also clear that the respondents are still aware of the need to protect themselves against COVID-19 but compliance may be difficult due to factors such as access and affordability of some of the safety protocols, such as face masks, hand sanitizers and the economic reality would not allow them to stay at home because they have to go out to fend for survival. Furthermore, there are several sources of information and knowledge on the pandemic as well as the safety measures, however, the mass media, especially the radio medium stood out as the most effective source. 


\section{Recommendations}

Based on the findings and conclusion, this study, therefore, recommends that:

- The WHO and other stakeholders with the help of the most effective information sources, need to enhance and intensify sensitization and reorientation on the fact that COVID-19 is not over yet and that there is increasing need to spread information to ensure comply with the safety practices, especially the realistically affordable practices such as frequent handwashing and social distancing.

- Stakeholders should consider maximum use of the mass media, especially radio for enhanced sensitisation and reorientation effort.

- The underutilized sources, especially community leaders should be fully utilized to promote the safety compliance through community dialogue.

- Develop or continually update inclusive response and risk communication and community engagement (RCCE) plans and strategies in all the LGA in Borno State.

- Introduce or boost inter-personal communication and community participatory approaches platforms for reorientation effort to comply with the safety measures by identifying and engage the services of community opinion leaders and influencers, peer educators and mentors for interpersonal communication approach.

- Intensify the use of digital tools and platforms, especially SMS and WhatsApp to buttress the need for compliance.

- There is also a need to improve the adaptation of behaviour change communication (SBCC) strategy to:

1) Increase knowledge by providing or ensuring exposure to high quality information about the pandemic and safety compliance by engaging health experts in media programmes and community dialogue and events.

2) Introduce edutainment in the SBCC approach, for example popular music artists could be used to enhance knowledge on COVID-19 and safety measures, especially the affordable but effective ones identified earlier.

3) Stimulate community dialogue and events on COVID-19 safety compliance through community-based social and biological groups (youth, elders, community leaders and gender-based fora/forums).

4) Evaluate the present media messages on safety compliance for possible change in the way information is framed. Since the media is a major source of information in Borno on the pandemic, media messages should be evaluated and reconsidered. 


\section{References}

AL-HANAWI, M. K., ANGAWI, K., ALSHAREEF, N., QATTAN A. M. N., HELMY, H. Z., ABUDAWOOD, Y., ALQURASHI, M., KATTAN, W. M., KADASAH, N. A., CHIRWA, G. C., \& ALSHARQI, O. (2020). Knowledge, attitude and practice toward COVID-19 among the public in the Kingdom of Saudi Arabia: A cross-sectional study. Frontiers in Public Health, 8(217), pp. 1-10. DOI: 10.3389/fpubh.2020.00217.

ALI, M. Y. \& BHATTI, R. (2020). COVID-19 (coronavirus) pandemic: Information sources channels for the public health awareness. Asia Pacific Journal of Public Health. Available from: https://doi.org/10.1177/.

ARRIAGA, P., ESTEVES, F., PAVLOVA, M. A., \& PIÇARRA, N. (2021). Editorial: Coronavirus disease (COVID-19): The impact and role of mass media during the pandemic. Frontiers in Psychology. DOI: 10.3389/fpsyg.2021.729238.

AWEKE, Z., JEMAL, B., MOLA, S., \& HUSSEN, R. (2020). Knowledge of COVID-19 and its prevention among residents of the Gedeo zone, South Ethiopia. Sources of information as a factor. Current Medical Research and Opinion, 36(12). Available from: https://doi.org/10.1080/03007995.2020.1835854

CDC (2014). Risk emergency + risk communication: CERC working with the media. Available from: https://emergency.cdc.gov/cerc/manual/index.asp.

CHOKSHI, D. A. (2018). Health, income, \& poverty: Where we are \& what could help. Available from: https://www.healthaffairs.org/do/10.1377/ hpb20180817.901935/full/

CINELLI, M., QUATTROCIOCCHI, W., GALEAZZI, A., VALENSISE, C. M., BRUGNOLI, E., SCHMIDT, A. L., ZOLA P., ZOLLO F., \& SCALA, A. (2020). The COVID-19 social media infodemic. Available from: https://arxiv.org/ pdf/2003.05004.pdf

City Population (2020). Gwoza local government area in Nigeria. Available from: https://www.citypopulation.de/php/nigeria-admin.php?adm2id=NGA008011

CRC (2020). ICRC response to COVID-19 in Nigeria. ICRC.

CUNNINGHAM, P. J. (2018). Why even healthy low-income people have greater health risks than higher-income people. Available from: https://www. commonwealthfund.org/blog/2018/healthy-low-income-people-greater-health-risks

KAYRITE, Q. Q., HAILU, A. S., TOLA, T. N., ADULA, T. D., \& LAMBYO, S. H. (2020). Compliance with COVID-19 preventive and control measures among food and drink establishments in Bench-Sheko and West-Omo Zones, Ethiopia. International Journal of General Medicine, pp. 1147-1155.

MARMOT, M. (2002). The influence of income on health: Views of an Epidemiologist. Health Affairs, 21(2). Available from: https://www.healthaffairs. org/doi/full/10.1377/hlthaff.21.2.31 
MAYKRANTZ, S. A., GONG, T., PETROLINO, A. V., NOBLING, B. D., \& HOUGHTON, J. D. (2020). How trust in information sources influences preventative measures compliance during the COVID-19 pandemic. International Journal of Environmental Research and Pubic Health, 18(5867). Available from: https://doi.org/10.3390/ ijerph18115867.

Nairametrics (2020). COVID-19 update in Nigeria. Available from: https:// nairametrics.com/2020/07/15/covid-19-update-in-nigeria/

NAVEENA, N. (2015). Importance of mass media in communicating health messages: An analysis. IOSR Journal of Humanities mand Social Science, 20(2), pp. 36-41.

NDHS (2019). Nigeria: Demographic and health survey. Abuja, National Population Commission.

Nigeria Health Watch (2020). Coronavirus: Time to take social distancing seriously in Nigeria. Available from: https://medium.com/@nigeriahealthwatch/ coronavirus-time-to-take-social-distancing-seriously-in-nigeria-8a059c881870

No face mask, no entering markets in Borno. Today, $25^{\text {th }}$ April, 2020. Available from: https://www.today.ng/news/nigeria/face-mask-entering-markets-borno-294382

ODORUME, A. (2015). Mass media health communication: Imperative for sustainable health development in Nigeria. Mgbakoigba: Journal of African Studies, 4(1).

OLAPEGBA, P. O., AYANDELE, O., KOLAWOLE, S. O., OGUNTAYO, R., GANDI, J. C., DANGIWA, A. L., OTTU, F. A., \& IORFA, S. K. (2020). A preliminary assessment of novel coronavirus (COVID-19) knowledge and perceptions in Nigeria. DOI: https:// doi.org/10.1101/2020.04.11.20061408

OLUBUNMI, A. P., OFURUM, O., \& TOB, L. E. (2016). Analysis of case studies in public health communication strategies in Nigeria. Research Journal of Mass Communication and Information Technology, 2(2), pp. 19-30.

ONWUZOO, A. (2020). COVID-19: Why regular handwashing is a challenge in Nigeria. Healthwise, 29 ${ }^{\text {th }}$ April, 2020. Available from: https://healthwise.punchng. com/covid-19-why-regular-hand-washing-is-a-challenge-in-nigeria/

OYAMA, O. \& OKPARA, N. (2017). Health communication: The responsibility of the media in Nigeria. Specialty Journal of Medical Research and Health Science, 2(3), pp. 1-4.

PADIDAR, S., LIAO, S., MAGAGULA, M. MAHLABA, T. A. M., NHLABATS, N. M., \& LUKAS, S. (2020). Assessment of early COVID-19 compliance to and challenges with public health and social prevention measures in the Kingdom of Eswatini, using an online survey. PLoS ONE, 16(6) Available from: https://doi.org/10.1371/ journal.pone.0253954 
PanAmerican Health Organisation (2020). COVID-19aninformative guide: Advice for journalists. Available from: https://iris.paho.org/handle/10665.2/52392.

REDMOND, N., BAER, H. J., CLARK, C. R., LIPSITZ, S., \& HICKS, L. S. (2010). Sources of health information related to preventive health behaviors in a national study. American Journal of Preventive Medicine, 38(6), pp. 620-627. DOI: https:// doi.org/10.1016/j.amepre.2010.03.001

SCHWARTZ, N. E. (1976). Nutrition knowledge, attitudes and practices of Canadian public health nurses. Journal of Nutrition Education, 8(1), pp. 28-31.

TANGCHAROENSATHIEN, V., CALUEJA, N., NGUYEN, T., PURNAT, T., D'AGOSTINO, M., GARCIA-SAISO, S., LANDRY, M., RASHIDIAN, A., HAMILTON, C., ABDALLAH, A., GHIGA, I., HILL, A., HOUGENDOBLER, D., VAN ANDEL, J., NUNN, M., BROOKS, I., SACCO, P. L., DE DOMENICO, M., MAI, P., GRUZD, A., ALAPHILIPPE, A., BRIAND, S. (2020). Framework for managing the COVID-19 infodemic: Methods and results of an online, crowdsourced WHO technical consultation. Journal of Medical Internet Research, 22(6), pp. 1-9. DOI: 10.2196/19659.

UNHCR (2020). Compliance status and over 2.7 million internally displaced persons (IDPs) in north-eastern Nigeria. Available from: https://www.unhcr.org/ nigeria-emergency.html

UoPeople (n.d). Benefits of education are societal and personal. Available from: https://www.uopeople.edu/blog/benefits-of-education-are-societal-andpersonal/

WHO (2005). Effective media communication during public health emergencies: A WHO handbook. Geneva: World Health Organisation.

WHO (2020). WHO scales up support as Borno State confirms COVID-19 outbreak. Available from: https://www.afro.who.int/news/who-scales-supportborno-state-confirms-covid-19-outbreak.

YAMEY, G. (2020). We have a cheap, effective way to keep ourselves safer from COVID-19. Why are we fighting about it? TIME, 29th June, 2020. Available from: https://time.com/5861295/masks-covid19-spread-fighting/ 